\title{
Longer shared parental leave is associated with longer duration of breastfeeding: a cross-sectional study among Swedish mothers and their partners
}

\author{
Maria Grandahl ${ }^{1 *}$, Jenny Stern ${ }^{1,2}$ and Eva-Lotta Funkquist ${ }^{1}$
}

\begin{abstract}
Background: Breastfeeding is associated with health benefits for both the mother and infant and is therefore important to support; moreover, parental leave is a beneficial factor for breastfeeding. The Swedish parental leave is generous, allowing each parent to take 90 days; additionally, a further 300 days can be taken by either parent. Generally, mothers take $70 \%$ of the parental leave days, mainly during the first year. However, breastfeeding duration has declined in the last decade, and it is not known how shared parental leave is associated with the duration of breastfeeding.
\end{abstract}

Aim: To investigate how parental leave is associated with the duration of exclusive and partial breastfeeding of the infant during the first 12 months after birth. An additional aim was to describe infants' and parents' characteristics and mode of birth in association with the duration of exclusive and partial breastfeeding.

Methods: This cross-sectional study was part of the Swedish Pregnancy Planning Study, conducted in Sweden in 2012-2015. The parents were recruited at 153 antenatal clinics in nine counties. In total, 813 couples completed a follow-up questionnaire 1 year after birth. Linear regression models were used to analyse the association between parental leave and the duration of breastfeeding.

Results: Infants were exclusively breastfed for, on average, 2.5 months (range 0-12 months) and partially breastfed, on average, 7 months (range $0-12$ months). Most of the parental leave was taken by the mother (mean $=10.9$ months) during the infant's first 12 months, while the partner took 3 months, on average. The parental leave (used and planned) during the infant's first 24 months were, on average, 21 months. In the multivariate linear regression analysis, mothers' and partners' high level of education $(p<0.001, p=0.044$, respectively), mothers' higher age $(p=$ $0.049)$, non-instrumental vaginal birth $(p=0.004)$ and longer parental leave for the first 24 months $(p<0.001)$ were associated with longer duration of partial breastfeeding.

Conclusion: The duration of partial breastfeeding was associated with higher parental educational level, higher age, non-instrumental vaginal birth and longer parental leave.

Keywords: Breastfeeding, Equal health, Infant, Mode of delivery, Parental leave, Partner, Socioeconomics

\footnotetext{
* Correspondence: Maria.Grandahl@kbh.uu.se

'Department of Women's and Children's Health, Uppsala University,

Akademiska sjukhuset, SE-751 85 Uppsala, Sweden

Full list of author information is available at the end of the article
}

(c) The Author(s). 2020 Open Access This article is licensed under a Creative Commons Attribution 4.0 International License, which permits use, sharing, adaptation, distribution and reproduction in any medium or format, as long as you give appropriate credit to the original author(s) and the source, provide a link to the Creative Commons licence, and indicate if changes were made. The images or other third party material in this article are included in the article's Creative Commons licence, unless indicated otherwise in a credit line to the material. If material is not included in the article's Creative Commons licence and your intended use is not permitted by statutory regulation or exceeds the permitted use, you will need to obtain permission directly from the copyright holder. To view a copy of this licence, visit http://creativecommons.org/licenses/by/4.0/ The Creative Commons Public Domain Dedication waiver (http://creativecommons.org/publicdomain/zero/1.0/) applies to the data made available in this article, unless otherwise stated in a credit line to the data. 


\section{Background}

The Word Health Organisation (WHO) recommends exclusive breastfeeding for 6 months and partial breastfeeding for 2 years or longer [1-3]. Breastfeeding is associated with many health benefits for both the mother and infant [4] and therefore, beneficial for society. If $90 \%$ of the new-borns in the United States were breastfed exclusively for 6 months, it would prevent 3340 maternal or child deaths, and save a total of $\$ 3$ billion in medical costs [5].

In Sweden, the breastfeeding rates peaked in 1996, when $72 \%$ of infants were breastfeeding at 6 months and $43 \%$ were doing this exclusively. Since then, the breastfeeding rates have declined; in 2017, 63\% of infants were breastfeeding at 6 months and 13\% were doing this exclusively [6]. The initiation rate of breastfeeding is still high and comparable to many low-income countries [7], but at 12 months, the prevalence is lower in Sweden (16\%) than, for example, in the US (27\%) or Norway (35\%) [4]. The reason for the decline has been discussed vigorously [8], but there is no consensus about causes. Moreover, the decline has been particularly difficult to explain when breastfeeding has been progressing in other high-income countries [9].

Several factors are associated with shorter period of breastfeeding, for instance, being a first-time mother, emotional distress during pregnancy, separation between infant and mother and giving birth by caesarean section [10-12]. There are also differences in the duration of breastfeeding due to sociodemographic factors such as age and socioeconomic status [13]. A recent review found that women in less privileged position, and women with less education have shorter duration of breastfeeding [14]. Similar findings have been reported in a population-based study in Norway [15]. In addition, a Swedish cohort study found that infants whose father had lower education were less likely to be breastfed up to 12 months of age [16]. In Sweden, breastfeeding rates were lower for mothers with disposable incomes in the first three quartiles than in the last quartile [17]. Nonetheless, even though the breastfeeding rates are influenced by socioeconomic status, the decline cannot be explained by the widening socioeconomic gap [18].

The United Nations' (UN) Sustainable Development Goals commit governments to ensure healthy lives and promote well-being for all [19]. Breastfeeding contributes to most of the goals and the achievement of a more prosperous and sustainable future for people and the planet. Different approaches have been identified for countries to achieve the goals, and one of these is paid parental leave [20]. Studies undertaken in the US, New Zealand and Europe indicate that paid parental leave supports initiation of and the duration of breastfeeding $[16,21-23]$ and increases exclusive breastfeeding [20].
Few studies have examined the association between paid paternal leave and the duration of breastfeeding. However, a Swedish register-based study found that infants whose fathers took parental leave were breastfed to a higher extent during the first 6 months compared to infants whose fathers had not taken parental leave [16].

Sweden has one of the most generous parental leave programmes in the world, which enables parents to stay at home with their child for a total of 480 days, while receiving up to $80 \%$ of their wages from the state. Ninety of these days are reserved for each parent. Statistics show that the mother takes about $70 \%$ of the days and the partner $30 \%$ and that the number of days taken by the partner is increasing. Most women (83\%) take parental leave on full-time basis during the first 12 months or longer. Fifteen per cent of the parents have an equal share of parental leave (at least 40/60). Twenty-five per cent of the fathers take parental leave for 6 months or longer. During the child's first year, both parents can take parental leave in the same period, for maximum 30 days. The partner also has the right to take 10 days of temporary leave in connection with a child's birth. As long as the child is under the age of one, parents have the right to full-time parental leave; moreover, until the child is 8 years old, they have the right to work parttime, with or without parental benefits [24].

To the best of our knowledge, how the distribution of parental leave between the parents affects breastfeeding has not been studied previously. Thus, the aim of the present study was to investigate how the duration of exclusive and partial breastfeeding of the infant during the first 12 months after birth is associated with parental leave. In addition, the aim was to describe the infants' and parents' characteristics and mode of birth in association with the duration of exclusive and partial breastfeeding.

\section{Methods \\ Study design, sample and procedure}

This cross-sectional study was part of a longitudinal project called 'the Swedish Pregnancy Planning Study' undertaken in 2012-2015 [25]. Antenatal clinics $(n=$ $215)$ in nine $(n=9 / 21)$ counties in Sweden were initially invited to participate, and $153(71 \%)$ agreed to participate. Midwives approached women $(n=5493)$ upon registration at the antenatal clinics. Women completed questionnaires (Q) in early pregnancy $(n=3389, \mathrm{Q} 1)$, third trimester $(n=2583, \mathrm{Q} 2)$ and one-year post-partum ( $n=1263, \mathrm{Q} 3)$. In connection with Q3, the women were also asked to distribute the Q3 to their partners (Q3p), and 823 partners completed the former. More details regarding the recruitment process are found in Fig. 1 and in Stern et al. [25]. For this study, we excluded participants if only the mother or only the partner had 


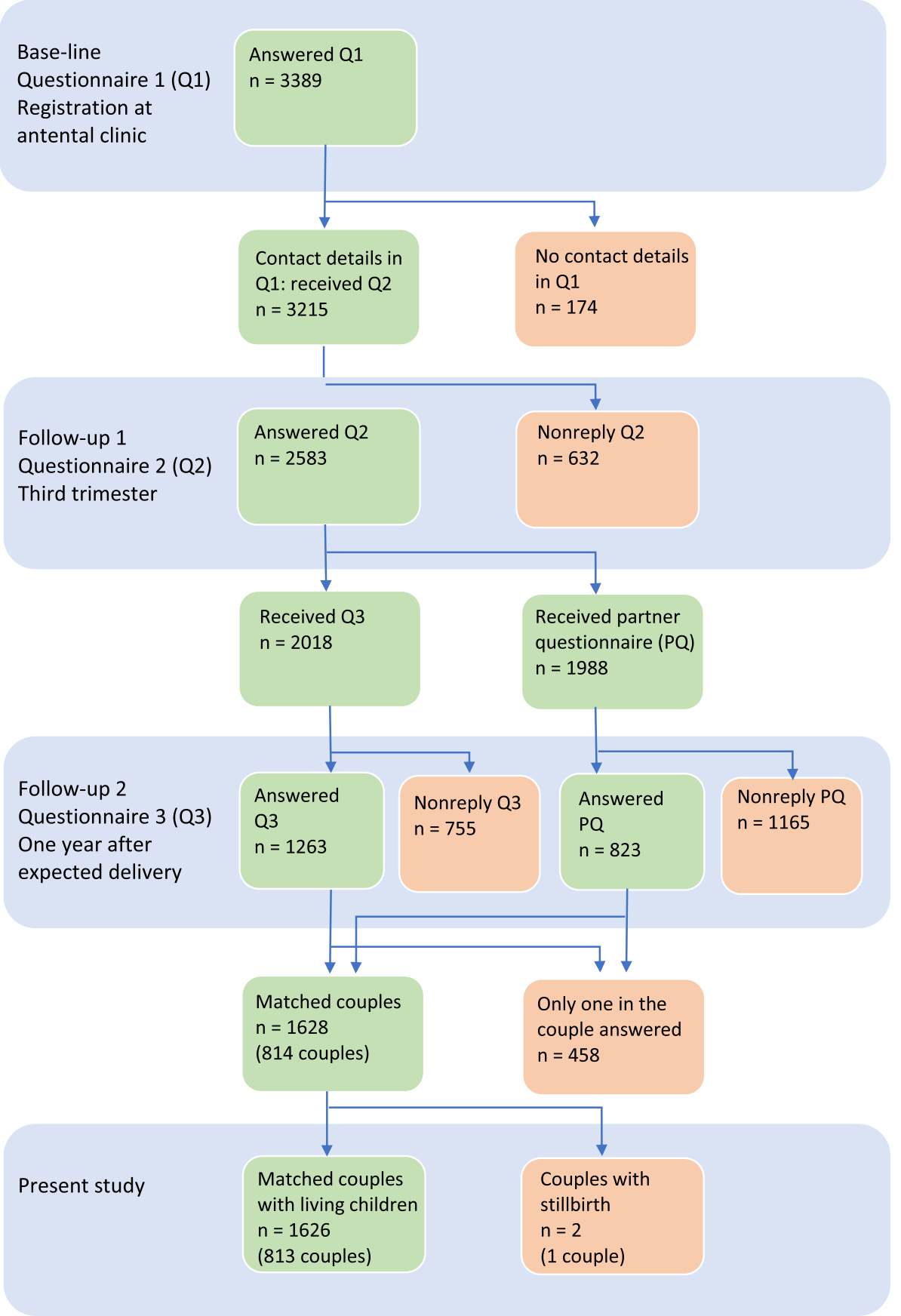

Fig. 1 Flowchart of eligible and participant parents

completed Q3, and couples who experienced stillbirth $(n=1)$. The final sample consisted of 813 matched couples (Fig. 1).

\section{Definitions}

We used the WHO definition that describes exclusive breastfeeding as when the infant eats only breast milk, with the supplement of vitamins and/or medications [26]. Partial breastfeeding means that the infant is given infant formula and/or food in addition to breastmilk. Parental leave was defined as time spent at home with the child, with or without parental benefit, and presented for the mother and the partner both separately and jointly.

\section{The questionnaires}

The mothers and their partners answered separate questionnaires 1 year after expected delivery. The questionnaires comprised a total of 65 questions. In the present 
study, we included data from questions about demographic background characteristics (age, sex, previous children, country of birth, level of education and household income), about the pregnancy (level of pregnancy planning, single/multiple pregnancy), mode of delivery (how it started, ended and if there was haemorrhage > $1000 \mathrm{ml}$ ), and about the infant (birth weight, gestational age, sex, neonatal care, congenital states and twins). The mothers and partners both reported their own use of parental leave, with or without parental benefit, for the first 12 months after delivery. Both parents also reported their planned use of parental leave for 24 months after birth. In addition, the mothers answered items about how the infant was fed during the first 12 months. For each month, they were asked to tick all of the following that applied to them: breast milk, infant formula, tiny little tastes $(1 \mathrm{ml})$, small samples (1-2 teaspoons) and food (> 1 tablespoon), see Additional file 1 for more details.

\section{Statistical analyses}

The Statistical Package for the Social Sciences version 25.0 (SPSS Inc., Chicago, Illinois, USA) was used for the statistical analyses. Sample characteristics are presented by descriptive statistics. Parental leave was operationalised as three measures at two different time periods, see Table 1. The association between the mother's and partner's parental leave was analysed using Pearson's correlation.

A linear regression was used to analyse the effect of background variables and parental leave (independent variables) on the duration of both exclusive and partial breastfeeding (dependent variables), respectively. Independent variables were chosen based on previous knowledge on breastfeeding [10-12, 14, 16, 20].

Independent variables on nominal and ordinal level were dichotomised as follows:

- level of education (lower than university education versus university education)

- country of birth (Sweden versus other/do not know)

- household income/month (low (<40,000 SEK/4000 EUR) versus average/high ( $>40,000$ SEK/4000 EUR)

- planned pregnancy (highly/quite planned versus quite/highly unplanned)

Table 1 Operationalisations of parental leave

\begin{tabular}{lll}
\hline & $\begin{array}{l}\text { Used weeks of parental } \\
\text { leave during the first } \\
12 \text { months after birth }\end{array}$ & $\begin{array}{l}\text { Used and planned } \\
\text { weeks of parental } \\
\text { leave during the } \\
\text { first 24 months } \\
\text { after birth }\end{array}$ \\
\hline Mother's parental leave & MPL12 & MPL24 \\
Partner's parental leave & PPL12 & PPL24 \\
Total parental leave & TPL12 & TPL24 \\
\hline
\end{tabular}

- previous children (no versus yes)

- neonatal care (no versus yes)

- congenital states in need of care (no versus malformation/injury/disease)

- mode of birth: start of delivery (spontaneous versus induced/planned caesarean section)

- mode of birth: end of delivery (normal versus instrumental/caesarean section or complications)

Independent variables were analysed at univariate level, and all significant variables were then included in the analysis at multivariate level. If both the mothers and/or the partners used and planned use of parental leave and the total used and planned use of parental leave was significant at univariate level, only the total was included in the multivariate model to avoid overlapping independent variables. A $p$-value of $<0.05$ was considered significant.

\section{Results}

\section{Sample and characteristics}

Mothers who participated in the study were between 19 and 49-years-old, and partners between 22 and 57-yearsold, see Table 2. Characteristics about the pregnancy, mode of birth and child are presented in Table 2 .

\section{Parental leave}

The mothers took, on average, 10.9 months of parental leave during the first year after birth (M: 43.7 weeks, SD: 7.4, range: 0-48). The corresponding figure for their partners was 3.0 months (M: 11.6 weeks, SD: 10.0, range: $0-48)$. The total use of parental leave during the first year after birth was, on average, 13.8 months (M: 55.4 weeks, SD: 9.8, range: 0-96). The mothers planned to take, on average, 4.0 months of parental leave during the second year after birth (M: 16.0 weeks, SD: 13.6, range: 0-12) and their partners 3.4 months (M: 13.5 weeks, SD: 10.8, range: 0-48). The average total use of and planned use of parental leave during the 24 months after birth was 21.0 months (M: 84.2 weeks, SD: 21.4, range: 0-192).

Figure 2 illustrates the used and planned use of parental leave for the first 24 months after birth. The mothers' and partners' total parental leave during the first 24 months (used and planned) was negatively correlated $(r=-0.85, p<0.001)$. Thus, the more parental leave used or planned by the partner, the less parental leave used or planned by the mother.

\section{Breastfeeding}

Infants were exclusively breastfed for, on average, 2.5 months (range 0-12) and breastfed to any extent, on average, 7 months (range $0-12$ ). 
Table 2 Background characteristics of the mother, partner, pregnancy, mode of birth and child

\begin{tabular}{|c|c|c|c|}
\hline Characteristics of study sample & $\begin{array}{l}\text { Study sample } \\
\text { Mean (SD) }\end{array}$ & $\begin{array}{l}\text { Study sample } \\
\text { Frequency (\%) }\end{array}$ & $\begin{array}{l}\text { Comparison } \\
\text { Official Statistics Sweden }\end{array}$ \\
\hline \multicolumn{4}{|l|}{ Mother } \\
\hline Age, years & $31.7(4.6)$ & & $30.3^{\mathrm{a}}$ \\
\hline Born outside Sweden & & $73(9)$ & $27.5^{\mathrm{b}}$ \\
\hline University education & & $475(58)$ & $49^{b}$ \\
\hline Previous children & & $415(51)$ & $56^{\mathrm{a}}$ \\
\hline \multicolumn{4}{|l|}{ Partner } \\
\hline Age, years & $34.3(5.5)$ & & $34.0^{\mathrm{a}}$ \\
\hline Sex: female & & $14(2)$ & $d$ \\
\hline Born outside Sweden & & $64(8)$ & 11.6 \\
\hline University education & & $349(43)$ & 38 \\
\hline High household income & & $510(63)$ & $550^{e}$ \\
\hline \multicolumn{4}{|l|}{ Pregnancy } \\
\hline \multicolumn{4}{|l|}{ Level of pregnancy planning } \\
\hline Highly planned & & $429(52)$ & $d$ \\
\hline Quite planned & & $215(26)$ & $d$ \\
\hline Neither planned nor unplanned & & $92(11)$ & $d$ \\
\hline Quite unplanned & & $28(3)$ & $d$ \\
\hline Highly unplanned & & $47(6)$ & $d$ \\
\hline Single pregnancy & & $792(97)$ & $98^{\mathrm{b}}$ \\
\hline Multiple pregnancy & & $5(0.6)$ & $1.4^{\mathrm{b}}$ \\
\hline \multicolumn{4}{|l|}{ Mode of delivery } \\
\hline Spontaneous vaginal & & $614(76)$ & $83^{b}$ \\
\hline Induced vaginal & & $132(16)$ & $16.7^{\mathrm{a}}$ \\
\hline Planned Caesarean & & $60(7)$ & $8^{b}$ \\
\hline \multicolumn{4}{|l|}{ Complications } \\
\hline Haemorrhage $^{9}$ (> 1000 ml) & & $57(7)$ & $7.2^{c}$ \\
\hline Emergency Caesarean & & $66(8)$ & $8^{\mathrm{a}}$ \\
\hline Instrumental delivery & & $65(8)$ & $7.2^{\mathrm{a}}$ \\
\hline \multicolumn{4}{|l|}{ Infant } \\
\hline Birth weight, grams & $3585(550.5)$ & & $3565^{b}$ \\
\hline Gestational age, weeks & $39(1.6)$ & & $39-40^{b}$ \\
\hline \multicolumn{4}{|l|}{ Sex } \\
\hline Girl & & $401(49.4)$ & $48.6^{b}$ \\
\hline Boy & & $410(50.5)$ & $51.3^{b}$ \\
\hline Neonatal care & & $46(6)$ & $\sim 10^{b, e}$ \\
\hline \multicolumn{4}{|l|}{ Congenital state in need of care } \\
\hline Malformation & & $12(1)$ & $2-3^{a}$ \\
\hline Injury & & $2(0.2)$ & \\
\hline Disease & & $19(2)$ & $3.7 / 1000^{\mathrm{a}}$ \\
\hline
\end{tabular}

a The National Board of Health and Welfare

b Statistics Sweden

${ }^{c}$ Vaginal (section $=10.4 \%$ )

${ }^{\mathrm{d}}$ No reliable data available

e $5.5 \%$ gestation week <37)

${ }^{\mathrm{f}}$ Children born with malformation or injury at birth

${ }^{g}$ Bleeding before, during or after the delivery 


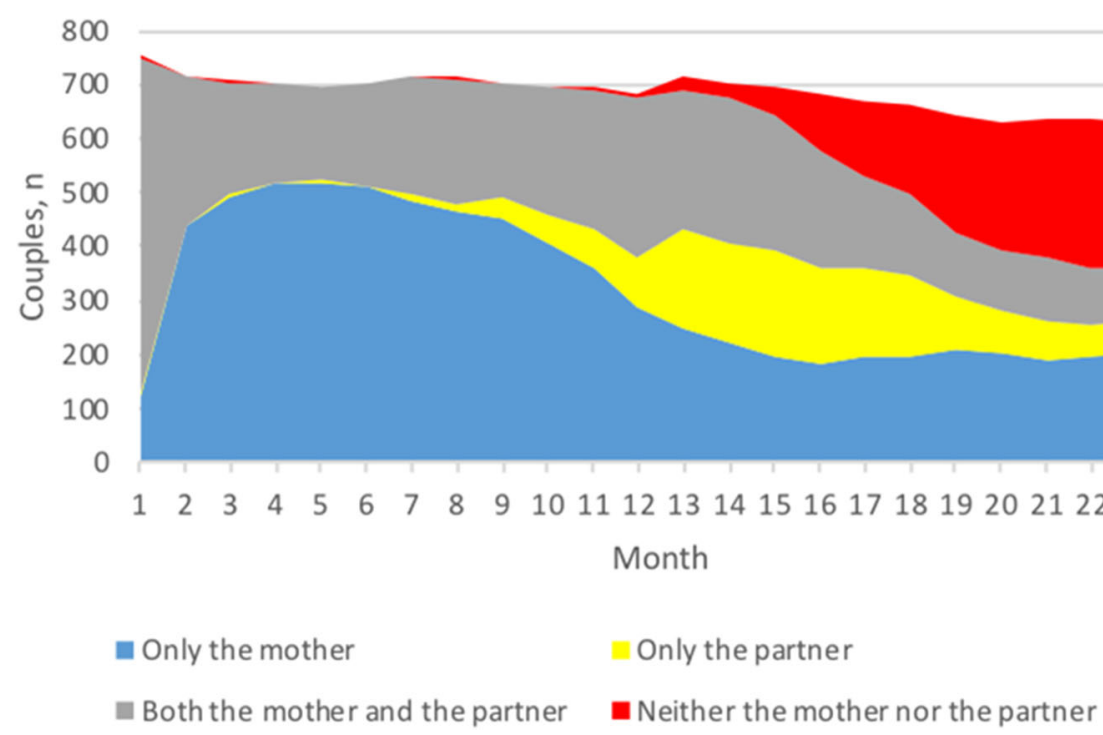

Fig. 2 Used and planned use of parental leave for the first two years after birth, with or without parental benefit.

\section{Factors associated with the duration of exclusive breastfeeding}

Variables associated with exclusive breastfeeding on univariate level were included in the multiple regression model and are presented in Table 3. In the multivariate linear regression analysis, higher maternal education, previous births, singleton pregnancy, normal delivery (start and end of delivery) and longer parental leave (TPL24) were associated with longer duration of exclusive breastfeeding (Table 3). The following variables were not associated with the duration of exclusive breastfeeding in the linear regression analysis on univariate level: partner's level of education, household income, partner's age, mother's country of birth, partner's country of birth, level of pregnancy planning, birth weight, sex of the infant, neonatal care, congenital state of the infant, mother's use of parental leave (MPL12), partner's use of parental leave (PPL12), total use of parental leave (TPL12), and partner's used and planned use of parental leave (PPL24) (data not shown).

\section{Factors associated with the duration of partial breastfeeding}

Variables associated with partial breastfeeding on univariate level were included in the multivariate model and are presented in Table 4. In the multivariate linear

Table 3 Results for univariate and multivariate linear regression models with the duration of exclusive breastfeeding during the first 12 months after birth as the outcome

\begin{tabular}{|c|c|c|c|c|c|c|}
\hline \multirow[b]{2}{*}{ Variables } & \multicolumn{4}{|c|}{ Univariate regression } & \multicolumn{2}{|c|}{ Multiple regression $^{\mathbf{a}}$} \\
\hline & $R$ Square & Adjusted $R$ Square & Beta-coefficient & $p$ & Beta-coefficient & $p$ \\
\hline Mother's level of education (low/high) & 0.020 & 0.018 & 2.145 & $<0.001$ & 1.723 & 0.004 \\
\hline Mother's age & 0.011 & 0.010 & 0.171 & 0.003 & 0.060 & 0.391 \\
\hline Gestational age & 0.006 & 0.004 & 0.341 & 0.034 & 0.299 & 0.089 \\
\hline Previous children & 0.021 & 0.019 & 2.152 & $<0.001$ & 1.826 & 0.002 \\
\hline Pregnancy, single versus multiple & 0.013 & 0.012 & -11.034 & 0.001 & -10.022 & 0.045 \\
\hline Mode of birth/start of delivery (spontaneous versus other) & 0.027 & 0.025 & -2.870 & $<0.001$ & -2.001 & 0.006 \\
\hline Haemorrhage in connection with delivery & 0.008 & 0.007 & -2.634 & 0.011 & -1.639 & 0.133 \\
\hline $\begin{array}{l}\text { Mode of birth/end of delivery (normal versus } \\
\text { instrumental/ caesarean) }\end{array}$ & 0.023 & 0.022 & -2.962 & $<0.001$ & -1.919 & 0.011 \\
\hline $\begin{array}{l}\text { The mother's used and planned use of parental } \\
\text { leave for the first } 24 \text { months }\end{array}$ & 0.005 & 0.004 & 0.032 & 0.038 & - & - \\
\hline $\begin{array}{l}\text { Total used and planned use of parental leave for } \\
\text { the first } 24 \text { months }\end{array}$ & 0.007 & 0.006 & 0.030 & 0.016 & 0.038 & 0.003 \\
\hline
\end{tabular}

${ }^{a}$ Model summary $R^{2}=0.094$ Adjusted $R^{2}=0.082$ 
Table 4 Results for univariate and multivariate linear regression models with the duration of any breastfeeding during the first 12 months after birth as the outcome

\begin{tabular}{|c|c|c|c|c|c|c|}
\hline \multirow[b]{2}{*}{ Variables } & \multicolumn{4}{|c|}{ Univariate regression } & \multicolumn{2}{|c|}{ Multiple regression ${ }^{\mathbf{a}}$} \\
\hline & $R$ Square & Adjusted $R$ Square & Beta-coefficient & $p$ & Beta-coefficient & $p$ \\
\hline Mother's level of education (low/high) & 0.066 & 0.065 & 7.553 & $<0.001$ & 5.005 & $<0.001$ \\
\hline Partner's level of education (low/high) & 0.035 & 0.033 & 5.406 & $<0.001$ & 2.340 & 0.044 \\
\hline Household income (low/high) & 0.013 & 0.012 & 3.264 & 0.001 & 0.077 & 0.945 \\
\hline Mother's age & 0.053 & 0.052 & 0.716 & $<0.001$ & 0.320 & 0.049 \\
\hline Partner's age & 0.029 & 0.028 & 0.443 & $<0.001$ & 0.157 & 0.198 \\
\hline Gestational age & 0.008 & 0.006 & 0.773 & 0.013 & 0.581 & 0.081 \\
\hline Single/multiple pregnancy & 0.012 & 0.010 & -19.381 & 0.002 & -13.379 & 0.155 \\
\hline $\begin{array}{l}\text { Mode of birth/start of delivery (spontaneous } \\
\text { versus other) }\end{array}$ & 0.011 & 0.010 & -3.584 & 0.003 & -1.373 & 0.314 \\
\hline $\begin{array}{l}\text { Mode of birth/end of delivery (normal versus } \\
\text { instrumental/caesarean) }\end{array}$ & 0.014 & 0.012 & -4.352 & 0.001 & -3.930 & 0.004 \\
\hline $\begin{array}{l}\text { The partner's used and planned use of parental } \\
\text { leave for the first } 24 \text { months }\end{array}$ & 0.020 & 0.019 & 0.124 & $<0.001$ & - & - \\
\hline $\begin{array}{l}\text { Total used and planned use of parental leave } \\
\text { for the first } 24 \text { months }\end{array}$ & 0.022 & 0.021 & 0.102 & $<0.001$ & 0.097 & $<0.001$ \\
\hline
\end{tabular}

${ }^{a}$ Model summary $R^{2}=0.143$ Adjusted $R^{2}=0.130$

regression analysis, higher level of mothers' and fathers' education, higher maternal age, normal delivery (normal versus instrumental/caesarean section or complications) and longer parental leave (TPL24) were associated with the duration of any breastfeeding (Table 4). The following variables were not associated with the duration of any breastfeeding in the linear regression analysis on univariate level: mother's country of birth, partner's country of birth, level of pregnancy planning, birth weight, sex of the infant, neonatal care, congenital state of the infant and haemorrhage in connection with delivery, mother's use of parental leave (MPL12), partner's use of parental leave (PPL12), total use of parental leave (TPL12), mother's used and planned use of parental leave (MPL24) (data not shown).

\section{Discussion}

The majority of both used and planned parental leave was taken by the mother. However, the more parental leave taken or planned by the partner, the less parental leave was taken or planned by the mother. Infants were exclusively breastfed for, on average, 2.5 months; moreover, the duration was associated with mothers' level of education, previous children, multiple pregnancy, mode of delivery (start and end) and total used and planned use of parental leave. Regarding the duration of partial breastfeeding, associated factors were mothers' and partners' level of education, mother's age, end of delivery and total used and planned use of parental leave. Consequently, mothers with higher level of education, higher age, normal end of delivery and living in a family with longer use of total parental leave had a longer duration of partial breastfeeding.

Breastfeeding is more than a choice; it is an investment in future health for both the mother and infant [27] and contributes to achieving many of the UNs 17 Sustainable Development Goals. Breastfeeding is linked to factors such as economy, health outcomes, sustainable consumption, gender equality and workplace rights [19]. The United Nations has pointed out paid parental leave as an important approach for countries in order to strengthen mothers' opportunity to breastfeed [20]. Several studies support this approach, since parental leave supports initiation of and the duration of breastfeeding [16, 21-23] and increases exclusive breastfeeding [20]. Maternal leave is frequently cited as a facilitator for breastfeeding [14], but paternal leave has also shown, in a Swedish study, to have positive impact on breastfeeding [16].

In our study, there was no association between parental leave during the first year and the duration of breastfeeding (exclusive or partial), either for the mother, partner or their total leave. It is not surprising that since almost all Swedish children stay at home with one parent during their first year, parental leave is not a decisive factor for breastfeeding in this setting. However the mothers' total parental leave was associated with the duration of exclusive breastfeeding and the partners' total parental leave with the duration of partial breastfeeding. The mothers' and partners' total parental leave during the first 2 years was associated with both exclusive and partial breastfeeding during the first year, also after adjusting for background factors, suggesting that 
the longer the total parental leave, the longer the duration of breastfeeding.

Support from the partner is an important factor for successful breastfeeding [28]; moreover, the partners' use of parental leave can be seen as an expression of support in caring for the child. Previous research has, for instance, shown that the longer the father was present at the ward after delivery, the longer the firsttime mother breastfed [29]. However, the question is complicated by the fact that one should distinguish between practical and emotional support, and that practical support from the partner could be a barrier to breastfeeding in high-income countries [30]. Interestingly, in the present study, we found no indication that partners' use of parental leave could be a barrier to breastfeeding. On the contrary, the longer the total used and planned use of parental leave, the longer the duration of total breastfeeding. Paid parental leave both facilitates parents and infant's relationship and promotes breastfeeding [21]. Furthermore, it improves overall child health and maternal mental health [31]. Partners' increased parental leave also highlights the need for partners to gain greater knowledge on how to support breastfeeding [32].

While breastfeeding is increasing in several countries [4], Sweden shows decreasing trend of breastfed infants in the most recent 10 years [8]. Consequently, the duration of time that mother's breastfed exclusively in this study was significantly lower than the recommendation of 6 months by WHO. The reasons for this might be multifactorial [10, 11, 27, 33]. Certain changes in Sweden in recent decades may have affected mothers who want to breastfeed and contributed to less incidences of breastfeeding. The proportion of caesarean sections as a mode of birth has increased in Sweden since the 1990s, from about 10 to $18 \%$ [34]. It is well known that mode of delivery is an important factor associated with successful breastfeeding initiation and duration [11]; moreover, a meta-analysis has reported negative association between planned caesarean section and early breastfeeding [12]. Thus, it is not surprising that mode of delivery was associated with the duration of breastfeeding, while spontaneous vaginal births resulted in more breastfeeding. Complicated deliveries might lead to disruption of the infant/mother dyad and thereby decrease initiation of breastfeeding. The Baby-friendly Hospital Initiative (BFHI) implemented by UNICEF and WHO is a successful and evidence-based programme to avoid separation and to support breastfeeding [27]. During the 1990s, Sweden was one of the countries that took a leading role in the implementation of BFHI, and $97 \%$ of all maternity care facilities were designated as baby-friendly in order to protect, promote and support breastfeeding [6]. However, the responsibility of meeting the standards of the
BFHI is no longer supervised in Sweden [26]. In order to deal with the decreasing trend in breastfeeding in Sweden, the programme needs to be a carefully reevaluated. Breastfeeding support must be a government priority, with an official body in charge of maintaining the BFHI standards.

The multivariate linear regression analysis showed that maternal factors such as high level of education and previous children were positively associated with the duration of exclusive breastfeeding. In addition, high maternal education level was positively associated with the duration of partial breastfeeding. This reaffirms previous research findings that mothers with high level of education and mothers with previous children are more likely to breastfeed $[10,35]$. Previous breastfeeding experience improves the ability to breastfeed, and parents with high level of education might have more flexibility regarding use of parental leave days, especially during the child's second year [36]. This might be a facilitating factor, resulting in longer duration of breastfeeding. Short or no breastfeeding may also be due to factors related to the infant. In the present study, it turned out that multiple pregnancy, i.e. twins, was a barrier to breastfeeding. This is also in line with previous research [37].

The duration of breastfeeding is a matter of equity and equal health among present and future generations. Promotion of breastfeeding in a high-income society such as Sweden is in line with the UNs and WHOs global goals and in the best interest of the individual child as well as overall public health. Consequently, parental leave might be one facilitating factor for successful breastfeeding in high-income societies. However, this subject is still quite unexplored. Future research is needed to understand why neither maternal nor partner parental leave during the first 12 months were associated with the duration of breastfeeding. We propose the use of qualitative research to explore how the duration of individual parental leave might be less relevant to breastfeeding than the total duration, as well as what factors parents believe are important for breastfeeding (exclusive and partial).

\section{Strengths and limitations}

This study is the first study investigating parental leave and the duration of breastfeeding among Swedish parents. The study provides data for a large number of Swedish parents $(n=1626)$, and the sample represents a wide geographical area, including both rural and urban areas with both high and low socioeconomic statuses.

The participants completed the questionnaires thoroughly; thus, the internal missing data was low. In addition, the items measuring breastfeeding duration (exclusive and partial) are very detailed and thereby 
probably more reliable than the Swedish register-based data [6], explaining the low duration in this study. However, the response rate for the present study is lower in comparison to the baseline data collection. It was challenging to collect data among the partners as we did not have any personal data on them. Consequently, we had to go through the participating women, and only 823 of 1988 eligible partners completed the partner questionnaire (Q3). Therefore, we could only match 813 couples from the initial cohort of 3389 pregnant women (Fig. 1). In addition, there might be a selection bias since the sample mainly includes Swedish-born parents. This is unfortunately common in research in general and similar studies among parents in particular. Furthermore, selfreported data should always be interpreted with caution. Even if the cross-sectional design cannot provide cause and effect, we used robust statistical analyses. Thus, we believe that the results might be representative of parents in similar contexts. In order to avoid too small subgroup analyses, we have categorised mode of delivery into normal versus instrumental/caesarean. This might be a strength as well as a limitation.

\section{Conclusion}

This is the first study investigating whether there is an association between mothers' and partners' duration of parental leave and exclusive and partial breastfeeding. The duration of exclusive breastfeeding was associated with mothers' level of education, previous children, multiple pregnancy, mode of delivery (start and end) and total used and planned use of parental leave. Our findings also indicate that there is an association between the duration of partial breastfeeding and mothers' and partners' level of education, mothers' higher age, end of delivery, and parents' total used and planned use of parental leave.

\section{Supplementary information}

Supplementary information accompanies this paper at https://doi.org/10. 1186/s12887-020-02065-1.

Additional file 1. Supplemental material Questionnaire, item breastfeeding and food first 12 months.

\section{ABBREVATIONS}

BFHI: Baby-Friendly Hospital Initiative.; UN: United Nation.; WHO: World Health Organisation.

\section{Acknowledgements}

We would like to thank all the healthcare providers for their assistance with the study.

\section{Authors' contributions}

All authors (MG, JS and E-L F) designed the study, participated in the analytic process, critically reviewed the manuscript and approved the manuscript as submitted.

\section{Authors' information}

MG is a PhD and a registered specialist nurse in paediatric care and in public health. JS is a PhD and registered nurse, specialising in public health. E-L Funkquist is a PhD, a registered nurse-midwife and a specialist nurse in paediatric care.

\section{Funding}

No external funding was received for this study.

\section{Availability of data and materials}

The datasets generated and analysed during the current study are not publicly available due to the risk of identifying participants but are available upon reasonable request. Principle Investigator for the Swedish Pregnancy Planning Study (SWEPP), Dr. Maria Jonsson (maria.jonsson@kbh.uu.se), Department of Women's and Children's Health, Uppsala University, Uppsala Sweden.

\section{Ethics approval and consent to participate}

We conducted the study according to the Declaration of Helsinki, and all women received oral and written information before giving their written consent. The participants were informed that participation was voluntary, and that they could withdraw at any time, for any or no given reason, without incurring any negative consequences for themselves. They were also informed that only the researchers would have access to the data and that all data would be presented on a group level. Contact details for the researchers were provided in case of further questions. The Swedish Ethical Review Authority approved this study, d.nr. 2010/085, with supplemental applications during the years (the same diary number).

\section{Consent for publication}

Not applicable.

\section{Competing interests}

The authors declare that they have no competing interests.

\section{Author details}

'Department of Women's and Children's Health, Uppsala University, Akademiska sjukhuset, SE-751 85 Uppsala, Sweden. ${ }^{2}$ Department of Health Promoting Science, Sophiahemmet University, Box 5605, SE-114 86 Stockholm, Sweden.

Received: 11 April 2019 Accepted: 1 April 2020

Published online: 14 April 2020

\section{References}

1. Smith HA, Becker GE. Early additional food and fluids for healthy breastfed full-term infants. Cochrane Database Syst Rev. 2016;8:CD006462.

2. Kramer MS, Kakuma R. Optimal duration of exclusive breastfeeding. Cochrane Database Syst Rev. 2002;1:CD003517.

3. World Health Organization, Health Topics, Breastfeeding [https://www.who. int/topics/breastfeeding/en/]. Accessed 12 Jan 2019.

4. Victora CG, Bahl R, Barros AJ, Franca GV, Horton S, Krasevec J, Murch S, Sankar MJ, Walker N, Rollins NC, et al. Breastfeeding in the 21st century: epidemiology, mechanisms, and lifelong effect. Lancet. 2016;387(10017): 475-90.

5. Bartick MC, Schwarz EB, Green BD, Jegier BJ, Reinhold AG, Colaizy TT, Bogen DL, Schaefer AJ, Stuebe AM. Suboptimal breastfeeding in the United States: Maternal and pediatric health outcomes and costs. Matern Child Nutr. 2017; 13(1):1-13.

6. National Board of Health and Welfare [Socialstyrelsen]: Statistics on Breastfeeding (Statistik om amning) 2019. https://www.socialstyrelsen.se/ globalassets/sharepoint-dokument/artikelkatalog/statistik/2019-9-6378.pdf. Accessed 15 Jan 2020

7. UNICEF, Ever breastfeeding rates by country [https://www.unicef.org/ nutrition/files/ever-breastfeeding-rates-by-country-2018.pdf]. Accessed 21 Feb 2019.

8. National Board of Health and Welfare [Socialstyrelsen]: Statistics on Breastfeeding [https://www.socialstyrelsen.se/statistik-och-data/statistik/ statistikamnen/amning/]. Accessed 12 Jan 2019. 
9. Bosso ET, Fulmer ME, Petersen R. Ten years of breastfeeding Progress: the role and contributions of the Centers for Disease Control and Prevention and our partners. Breastfeed Med. 2018;13(8):529-31.

10. Cato K, Sylven SM, Lindback J, Skalkidou A, Rubertsson C. Risk factors for exclusive breastfeeding lasting less than two months-identifying women in need of targeted breastfeeding support. PLoS One. 2017;12(6):e0179402.

11. Cohen SS, Alexander DD, Krebs NF, Young BE, Cabana MD, Erdmann P, Hays $N P$, Bezold CP, Levin-Sparenberg E, Turini M, et al. Factors associated with breastfeeding initiation and continuation: a meta-analysis. J Pediatr. 2018; 203:190-6 e121.

12. Prior E, Santhakumaran S, Gale C, Philipps LH, Modi N, Hyde MJ. Breastfeeding after cesarean delivery: a systematic review and meta-analysis of world literature. Am J Clin Nutr. 2012;95(5):1113-35.

13. Smith HA, OBH J, Kenny LC, Kiely M, Murray DM, Leahy-Warren P. early life factors associated with the exclusivity and duration of breast feeding in an Irish birth cohort study. Midwifery. 2015;31(9):904-11.

14. Navarro-Rosenblatt D, Garmendia ML. Maternity leave and its impact on breastfeeding: a review of the literature. Breastfeed Med. 2018;13(9):589-97.

15. Kristiansen AL, Lande B, Overby NC, Andersen LF. Factors associated with exclusive breast-feeding and breast-feeding in Norway. Public Health Nutr. 2010;13(12):2087-96

16. Flacking $R$, Dykes $F$, Ewald $U$. The influence of fathers' socioeconomic status and paternity leave on breastfeeding duration: a population-based cohort study. Scand J Public Health. 2010;38(4):337-43.

17. Wallby $T$, Hjern A. Region of birth, income and breastfeeding in a Swedish county. Acta Paediatr. 2009;98(11):1799-804.

18. Magnusson M, Lagerberg D, Wallby T. No widening socioeconomic gap within a general decline in Swedish breastfeeding. Child Care Health Dev. 2016:42(3):415-23.

19. United Nations. Sustainable Development Goals. https:/www.un.org/ sustainabledevelopment/sustainable-development-goals/. Accessed 12 Jan 2019.

20. Heymann J, Sprague AR, Nandi A, Earle A, Batra P, Schickedanz A, Chung PJ, Raub A. Paid parental leave and family wellbeing in the sustainable development era. Public Health Rev. 2017;38:21.

21. Cooklin AR, Rowe HJ, Fisher JR. Paid parental leave supports breastfeeding and mother-infant relationship: a prospective investigation of maternal postpartum employment. Aust N Z J Public Health. 2012;36(3):249-56.

22. de Lauzon-Guillain B, Thierry X, Bois C, Bournez M, Davisse-Paturet C, Dufourg MN, Kersuzan C, Ksiazek E, Nicklaus S, Vicaire H, et al. Maternity or parental leave and breastfeeding duration: results from the ELFE cohort. Matern Child Nutr. 2019;15(4):e12872.

23. Mirkovic KR, Perrine CG, Scanlon KS. Paid maternity leave and breastfeeding outcomes. Birth. 2016:43(3):233-9.

24. Swedish Social Insurance Agency [Försäkringskassan]. Social Insurance in Figures 2019. Stockholm: Swedish Social Insurance Agency; 2019. https:// www.forsakringskassan.se/wps/wcm/connect/cec4cea8-1d6c-4895-b442-bc3 b64735b09/socialforsakringen-i-siffror-2019-engelsk.pdf?MOD= AJPERES\&CVID=. Accessed 15 Jan 2020.

25. Stern J, Salih Joelsson L, Tyden T, Berglund A, Ekstrand M, Hegaard H, Aarts C, Rosenblad A, Larsson M, Kristiansson P. Is pregnancy planning associated with background characteristics and pregnancy-planning behavior? Acta Obstet Gynecol Scand. 2016;95(2):182-9.

26. Kramer MS, Kakuma R. Optimal duration of exclusive breastfeeding. Cochrane Database Syst Rev. 2012:8:CD003517.

27. Rollins NC, Bhandari N, Hajeebhoy N, Horton S, Lutter CK, Martines JC, Piwoz EG, Richter LM, Victora CG. Lancet breastfeeding series G: why invest, and what it will take to improve breastfeeding practices? Lancet. 2016; 387(10017):491-504

28. Mahesh PKB, Gunathunga MW, Arnold SM, Jayasinghe C, Pathirana S, Makarim MF, Manawadu PM, Senanayake SJ. Effectiveness of targeting fathers for breastfeeding promotion: systematic review and meta-analysis. BMC Public Health. 2018;18(1):1140.

29. Ekstrom A, Widstrom AM, Nissen E. Breastfeeding support from partners and grandmothers: perceptions of Swedish women. Birth. 2003;30(4):261-6.

30. Emmott EH, Mace R. Practical support from fathers and grandmothers is associated with lower levels of breastfeeding in the UK millennium cohort study. PLoS One. 2015;10(7):e0133547.

31. Bullinger $L R$. The effect of paid family leave on infant and parental health in the United States. J Health Econ. 2019;66:101-16.

32. Furman L, Killpack S, Matthews L, Davis V, O'Riordan MA. Engaging InnerCity fathers in breastfeeding support. Breastfeed Med. 2016;11(1):15-20.
33. Furuta M, Sandall J, Cooper D, Bick D. Severe maternal morbidity and breastfeeding outcomes in the early post-natal period: a prospective cohort study from one English maternity unit. Matern Child Nutr. 2016; 12(4):808-25.

34. National Board of Health and Welfare [Socialstyrelsen]: The Swedish Medical Birth Register [https://www.socialstyrelsen.se/en/statistics-anddata/registers/register-information/the-swedish-medical-birth-register/]. Accessed 12 Jan 2019.

35. Mangrio E, Persson K, Bramhagen AC. Sociodemographic, physical, mental and social factors in the cessation of breastfeeding before 6 months: a systematic review. Scand J Caring Sci. 2018;32(2):451-65.

36. Swedish Social Insurance Agency [Försäkringskassan]: Uttaget av föräldrapenning skiljer sig år beroende på inkomst [https://www. forsakringskassan.se/wps/wcm/connect/54b77e43-b626-4b9f-a27c-a093953 8aece/korta-analyser-2018-4.pdf?MOD=AJPERES\&CVID]. Accessed 15 Jan 2020.

37. Ostlund A, Nordstrom M, Dykes F, Flacking R. Breastfeeding in preterm and term twins--maternal factors associated with early cessation: a populationbased study. J Hum Lact. 2010;26(3):235-41 quiz 327-239.

\section{Publisher's Note}

Springer Nature remains neutral with regard to jurisdictional claims in published maps and institutional affiliations.
Ready to submit your research? Choose BMC and benefit from:

- fast, convenient online submission

- thorough peer review by experienced researchers in your field

- rapid publication on acceptance

- support for research data, including large and complex data types

- gold Open Access which fosters wider collaboration and increased citations

- maximum visibility for your research: over $100 \mathrm{M}$ website views per year

At BMC, research is always in progress.

Learn more biomedcentral.com/submissions 